
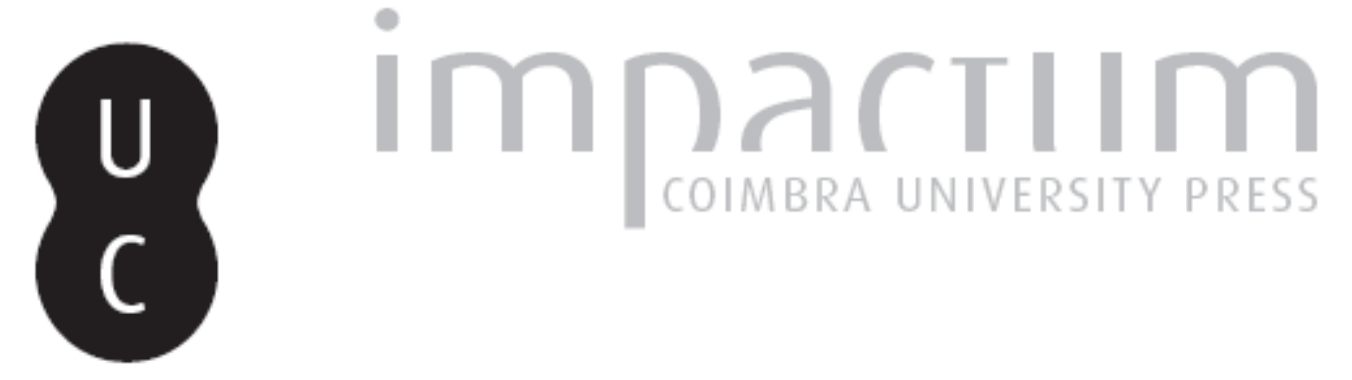

Segurança e gestão do risco no turismo de natureza

Autor(es): $\quad$ Neves, Daniel Márcio Fernandes

Publicado por: Associação Portuguesa de Riscos, Prevenção e Segurança

URL persistente:

URI:http://hdl.handle.net/10316.2/35846

DOI:

DOI:http://dx.doi.org/10.14195/1647-7723_20_13

Accessed : $\quad$ 26-Apr-2023 12:28:35

A navegação consulta e descarregamento dos títulos inseridos nas Bibliotecas Digitais UC Digitalis, UC Pombalina e UC Impactum, pressupõem a aceitação plena e sem reservas dos Termos e Condições de Uso destas Bibliotecas Digitais, disponíveis em https://digitalis.uc.pt/pt-pt/termos.

Conforme exposto nos referidos Termos e Condições de Uso, o descarregamento de títulos de acesso restrito requer uma licença válida de autorização devendo o utilizador aceder ao(s) documento(s) a partir de um endereço de IP da instituição detentora da supramencionada licença.

Ao utilizador é apenas permitido o descarregamento para uso pessoal, pelo que o emprego do(s) título(s) descarregado(s) para outro fim, designadamente comercial, carece de autorização do respetivo autor ou editor da obra.

Na medida em que todas as obras da UC Digitalis se encontram protegidas pelo Código do Direito de Autor e Direitos Conexos e demais legislação aplicável, toda a cópia, parcial ou total, deste documento, nos casos em que é legalmente admitida, deverá conter ou fazer-se acompanhar por este aviso. 


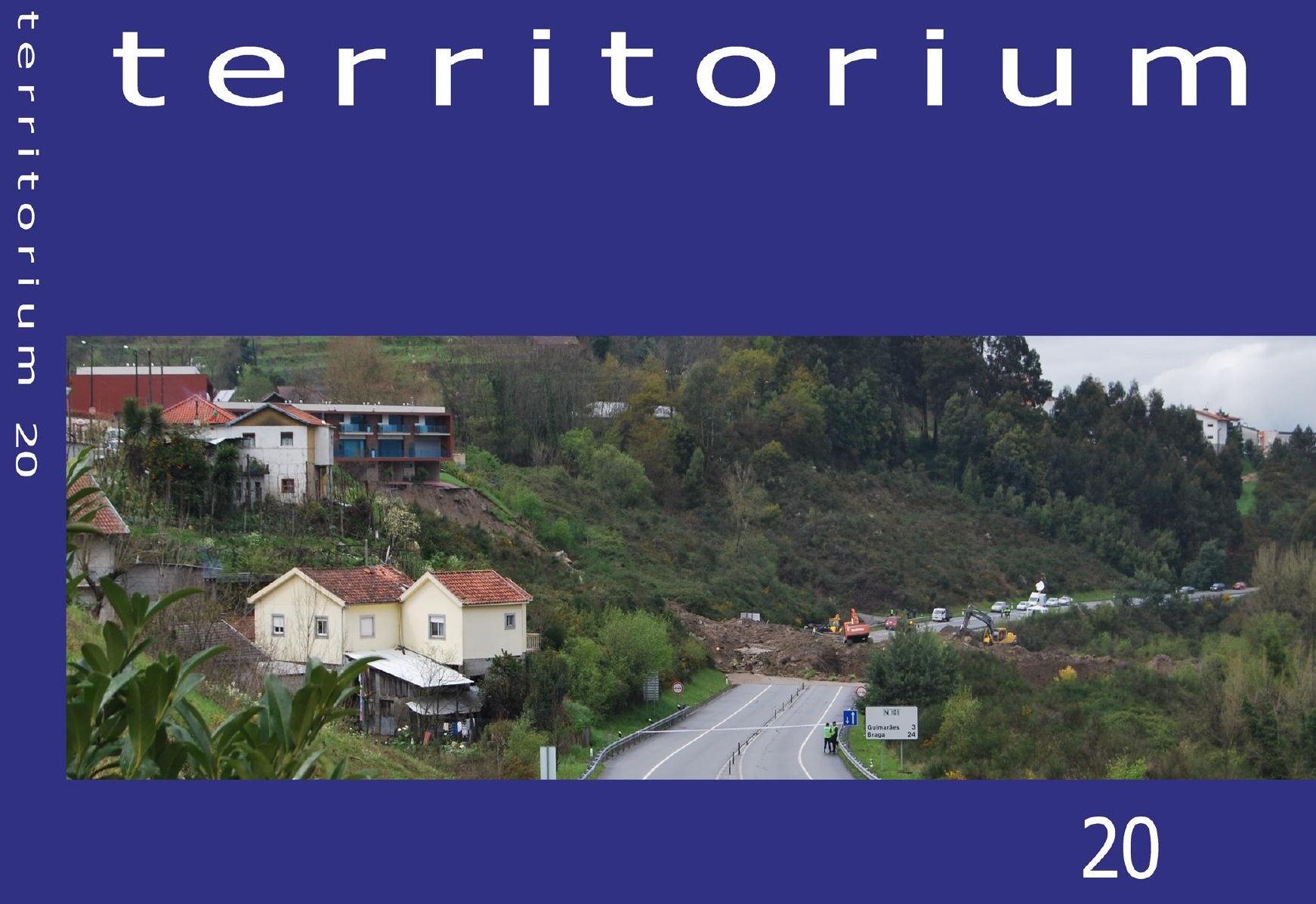

Riscos, População e Segurança 


\section{SEGURANÇA E GESTÃO DO RISCO NO TURISMO DE NATUREZA*}

Daniel Márcio Fernandes Neves

Instituto de Investigação Interdisciplinar da Universidade de Coimbra, Portugal daniel.nevespc@gmail.com

\section{RESUMO}

O risco é um conceito cada vez mais presente no turismo, sobretudo associado ao comportamento humano, o qual torna mais evidente a vulnerabilidade de um determinado território. As questões de segurança (Safety and Security) desempenham um papel vital nas actividades desenvolvidas pelas pessoas nas viagens e nas estadas em locais situados fora do seu enquadramento habitual.

Tendo-se constatado que os eventos catastróficos são responsáveis pela maioria das crises turísticas vividas nos últimos tempos, surge a necessidade de investigar a gestão do risco no turismo, suas consequências e antecedentes de forma mais profunda, nomeadamente em territórios insulares.

Palavras-chave: Segurança, turismo de natureza, aventura, gestão do risco.

\section{RESUMEN}

Gestión de la Seguridad y el Riesgo en Turismo de Naturaleza - El riesgo es un concepto cada vez más presente en el turismo, principalmente asociados con el comportamiento humano, que se hace más evidente la vulnerabilidad de un territorio determinado. Las cuestiones de seguridad desempeñan un papel vital en las actividades realizadas por las personas en el viaje y la estancia en lugares distintos al de su entorno habitual.

Y se encontró que los eventos catastróficos son responsables de la mayoría de las crisis turísticos experimentados en los últimos tiempos, hay una necesidad de investigar la gestión del riesgo en el sector turístico, sus antecedentes y consecuencias más profundamente, sobre todo en los territorios insulares.

Palabras clave: Seguridad, turismo de naturaleza, aventura, gestión de riesgos.

\section{RÉSUMÉ}

Sécurité et gestion des risques en tourisme de nature- Le risque est un concept de plus en plus présente dans le tourisme, principalement lié au comportement humain, qui devient plus évidente la vulnérabilité d'un territoire particulier. Les questions de sécurité (sécurité et sûreté) jouent un rôle essentiel dans les activités menées par les personnes dans le voyage et le séjour dans des endroits en dehors de leur environnement habituel.

Et il a été constaté que les catastrophes sont responsables de la plupart des crises touristiques expérimentés dans ces derniers temps, il est nécessaire d'enquêter sur la gestion des risques dans le tourisme, ses antécédents et les conséquences plus profondément, en particulier dans les territoires insulaires.

Mots-clé: Sécurité, tourisme de nature, aventure, gestion des risques.

\section{ABSTRACT}

Security and Risk Management in Nature Tourism - The Risk is a concept increasingly present in tourism, mainly associated with human behavior, which becomes more evident the vulnerability of a particular territory. Security issues (Safety and Security) play a vital role in the activities undertaken by people in the travel and stay in places outside their usual environment.

And it was found that catastrophic events are responsible for most of the tourist crises experienced in recent times, there is a need to investigate risk management in tourism, its antecedents and consequences more deeply, particularly in island territories.

Keywords: Safety, nature tourism, adventure, risk management.

\footnotetext{
* O texto deste artigo corresponde à comunicação apresentada ao VII Encontro Nacional de Riscos e I Forum ISCIA, tendo sido submetido para revisão em 26-11-2012, e aceite para publicação em 05-02-2013.

Este artigo é parte integrante da Revista Territorium, n. ${ }^{\circ} 20,2013,{ }^{\circ}$ RIscos, ISBN: 0872- 8941.
} 


\section{Introdução}

A comunidade científica sente cada vez mais a necessidade de estudar as dinâmicas sociais (comportamento humano / vulnerabilidade social) e os riscos naturais e tecnológicos, ou seja, causas que provocam ameaça ao homem e aos seus bens. Já muito se tem feito nesta matéria mas, não é possível eliminar por completo tais perigos nem controlar completamente os factores de risco que têm causado perturbação na vida a milhares de pessoas em todo o mundo.

O meio mais eficaz para reduzir as consequências ambientais, económicas e sociológicas dos riscos, são as medidas de prevenção e mitigação que podem permitir implementar medidas de ordenamento do território que evitem, em grande parte, as perdas humanas e económicas. Estudos sobre a importância de riscos naturais em termos económicos e sociais são imprescindíveis para o ordenamento do território, planificação, urbanismo, obras públicas e instalações industriais, planos de emergência e de protecção civil e protecção do meio ambiente.

Saliente-se que é crucial colocar o risco como função da perigosidade e da vulnerabilidade, visto que as medidas de mitigação actuam quase sempre sobre a redução da vulnerabilidade, retirando as pessoas dos lugares perigosos ou dando-lhe meios de resistência ou de resiliência. Contudo, a prevenção é possível e pode contribuir de forma eficaz para evitar perdas de vidas humanas e consequentemente, permitir uma abordagem mais eficiente das acções a levar a cabo pelos Agentes de Protecção Civil, na preparação e resposta as acções de protecção e socorro, bem como na fase de reabilitação e recuperação da sociedade, economia e do ambiente.

Os conceitos associados ao risco e que ao longo do presente trabalho assumem especial destaque são vários, sendo por isso essencial efectuar a sua desagregação e a explicação de cada um deles. Considerando que os termos relacionados com os diversos conteúdos do processo de avaliação do risco têm sido objecto de estudo e discussão científica um pouco por todo o mundo e que, embora sejam mais ou menos específicos das ciências cindínicas e comuns às várias áreas dos saberes cindínicos, nem sempre são entendidos por todos com o mesmo significado, o que muito provavelmente se deve ao facto destas ciências serem ainda muito recentes. As interligações entre os principais conceitos encontram-se representadas na fig. 1 .

Para clarificar os conceitos supramencionados, adoptouse as definições implícitas no Guia Metodológico para a Produção de Cartografia Municipal de Risco, que teve como objectivo harmonizar e simplificar os termos associados ao risco. A análise da vulnerabilidade pretende identificar "quem" e "o quê" vai ser afectado e "com que gravidade", no caso de ocorrer um acidente grave ou uma catástrofe. A vulnerabilidade das diversas sociedades aos perigos, muitas vezes criados por elas, reflecte o diferente grau de preparação de cada uma face a esses fenómenos, que depende da qualidade dos mecanismos e medidas de prevenção/mitigação, planeamento/preparação, resposta/emergência e recuperação/reabilitação.

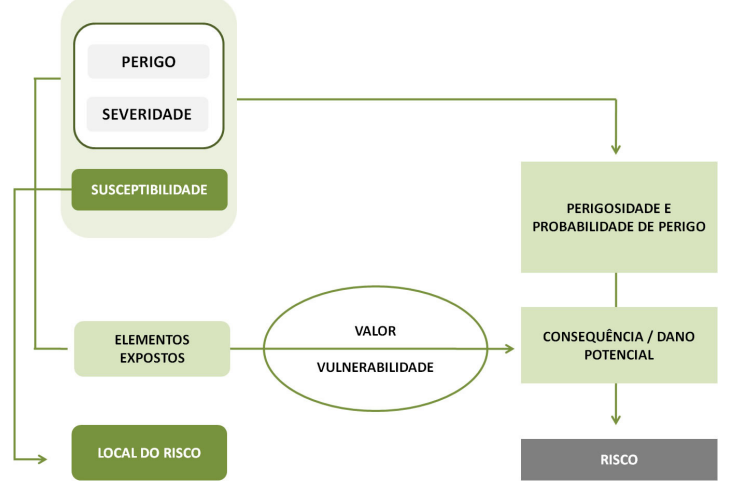

Fig. 1 - Interligação dos Conceitos Subjacentes ao Risco. Fonte: JuLĩ̃o et al., 2009.

Não é por acaso que o mesmo fenómeno, ocorrendo com igual intensidade em sociedades distintas, pode provocar fortes disfunções numa e não afectar outra. É a ocupação desordenada do território que tem conduzido ao aumento da vulnerabilidade. A má gestão territorial leva a intervenções pesadas de protecção que ao criar uma falsa sensação de segurança para novas localizações próximas da zona de risco, conduzem a uma incontrolável espiral de custos.

O processo de análise da vulnerabilidade começa, em geral, pela identificação dos perigos com maior probabilidade de originarem uma situação de emergência. 0 propósito é identificar quais os que representam uma ameaça mais significativa e que devem ser prioritários na aplicação de mecanismos e medidas de gestão do risco e da emergência. A mera existência de um perigo não coloca, por si só, a comunidade em risco, neste sentido é fulcral compreender a área em estudo nas diferentes componentes que a constituem, a humana, a material e a natural (fig. 2).

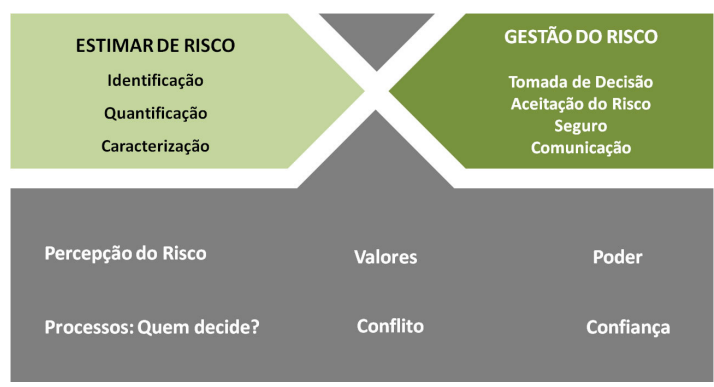

Fig. 2 - Componentes da Análise de Risco. Fonte: Adaptado de Solvic, 2010.

Os estudos, análises técnicas e quantitativas dos riscos foram realizados predominantemente nos anos 
60, por várias disciplinas, sobretudo a Toxicologia, a Epidemiologia, a Psicologia e as Engenharias. $\mathrm{Na}$ perspectiva destas disciplinas o risco é entendido como um evento adverso, uma actividade, um atributo físico com probabilidade lógica de produzir danos, e que pode ser estimado por meio de cálculos quantitativos de níveis de aceitabilidade, adoptando diversos métodos (predições estatísticas, estimação probabilística do risco, comparações de risco/benefício, análises psicométricas) que permitem definir estratégias de gestão do risco (GUIVANT, 1998).

No domínio do estudo da percepção do risco, o autor descreve três abordagens: paradigma axiomático (focaliza o modo como as pessoas reflectem o noção dos riscos bem delineados como taxa de mortalidade, probabilidade de ocorrência de perda financeira, nas vidas das pessoas); paradigma sociocultural (estuda os efeitos das variações do grupo e da cultura na percepção de risco); paradigma psicotécnico (procura compreender as distintas reacções emocionais das pessoas frente às situações de risco). Segundo Stovic (2002), uma boa estratégia para compreender o risco percebido é desenvolver uma taxonomia para os perigos, a qual pode ser usada para compreender e predizer as respostas aos riscos. Contudo, ao depreender-se que os riscos são percebidos e regulados em função de princípios referentes à organização social, inviabilizase a neutralidade no tratamento dos riscos, dada pelas ferramentas metodológicas quantitativas.

A determinação da aceitabilidade dos riscos constituise uma abordagem culturalista em relação às teorias objectivistas. Segundo GuIvant (1998), os níveis aceitabilidade do risco são apenas um dos factores que devem ser explorados, pois a forma pela qual se determinam os níveis aceitáveis de qualidade de vida, bem como os de moralidade e decência, também deva ser relacionada à discussão. Neste sentido, uma análise mais completa considera a influência dos valores sociais e culturais na percepção dos riscos como variável determinante na configuração da relação do indivíduo com os riscos.

A análise de riscos consiste no desenvolvimento do saber acerca dos mesmos, do seu conhecimento e dos mecanismos de controlo que podem minimizar o seu impacte, permitindo estimar a probabilidade e as suas consequências expectáveis, conduzindo à determinação do respectivo nível de risco existente (fig. 3).

\section{Legislação Referência para Governação de Riscos no Turismo em Portugal}

A simbiose entre o Turismo e os Riscos é ainda pouco consistente em Portugal, tornando-se assim muito difícil encontrar legislação que regule os Riscos na sua vertente

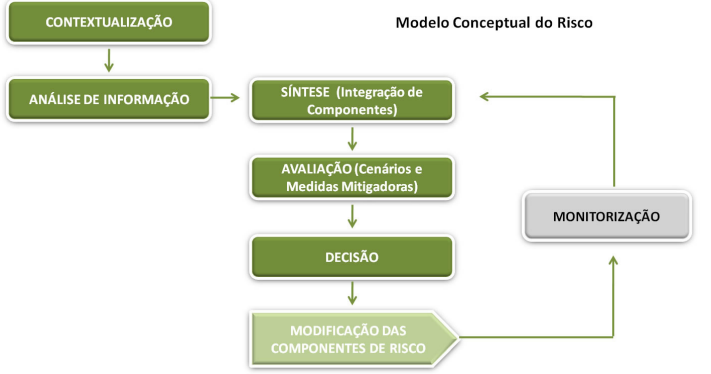

Fig. 3 - Modelo Conceptual de Risco. Fonte: ToBin e MonTz, 1997.

"safety", num conceito de Turismo. É da competência do "Turismo de Portugal, I.P.", entre outras, a missão incentivar o investimento no sector do turismo, a qualificação e desenvolvimento das infra-estruturas turísticas, a coordenação da promoção interna e externa de Portugal como destino turístico e o desenvolvimento da formação de recursos humanos do sector, conforme o Decreto-Lei n 141/2007 de 27 de Abril.

De referir que apesar de não haver relação directa com a temática a abordar (Turismo/Riscos), nas últimas décadas têm sido criadas diversas medidas legislativas que visam a prevenção de riscos nas mais variadas áreas e que indirectamente têm influência na segurança da vertente turística (Turistas e Infra-estruturas Turísticas), por exemplo: Decreto-Lei n. ${ }^{\circ} 243 / 86$, de 20 de Agosto, que aprova o Regulamento Geral de Segurança e Higiene do Trabalho nos Estabelecimentos Comerciais, de Escritório e Serviços e a Publicação pelo ISHST (ACT), em 2005, do Manual de Prevenção para a Hotelaria e Restauração da UNIHSNOR - União das Associações de Hotelaria e Restauração do Norte de Portugal.

Estas normas legais visam sobretudo concretizar alguns objectivos, como a identificação dos fundamentos da saúde e segurança no trabalho, identificar e aplicar a legislação de trabalho relacionada com as actividades de animação turística, identificar e aplicar técnicas de gestão de riscos, identificar e aplicar medidas de protecção e prevenção em ambiente de trabalho e aplicar métodos de actuação em caso de acidente.

Sendo Portugal um País com tradições turísticas, existe um vasto leque de legislação que apesar de não ser exclusiva para a atividade turística enquadra-se no conceito "Turismo Seguro".

No domínio das ciências do risco, destaca-se o Decreto-Lei n. ${ }^{\circ}$ 220/2008 de 12 de Novembro que estabelece o regime jurídico da segurança contra incêndios em edifícios; a Resolução do Conselho de Ministros $n^{\circ} 152 / 2001$, de 11 de Outubro - que estabelece a Estratégia Nacional de Conservação da Natureza e da Biodiversidade; Decreto-Lei n. ${ }^{\circ}$ 39/2008, de 07.03 - Aprova o regime jurídico dos empreendimentos turísticos. Portaria n. ${ }^{\circ} 327 / 2008$, 
de 28.04 - Aprova o sistema de classificação dos estabelecimentos hoteleiros, aldeamentos turísticos e apartamentos turísticos; Portaria n. ${ }^{\circ} 937 / 2008$, de 25.06 - Estabelece os requisitos mínimos a observarem pelos estabelecimentos de turismo de habitação e de turismo no espaço rural; Portaria n. ${ }^{\circ} 1320 / 2008$ de 17.11 - Estabelece os requisitos específicos de instalação, classificação e funcionamento dos parques de campismo e caravanismo; Decreto-Lei n. ${ }^{\circ} 371 / 2007$ de 06.11) Torna obrigatória a existência e disponibilização do livro de reclamações a todos os fornecedores de bens e prestadores de serviços que tenham contacto com o público, com excepção dos serviços e organismos da Administração Pública; Decreto-Lei n. ${ }^{\circ}$ 65/97, de 31.03 - Regula a instalação e o funcionamento dos recintos com diversões aquáticas; Decreto Regulamentar n. ${ }^{\circ}$ 5/97, de 31.03 - Regulamenta as condições técnicas e de segurança dos recintos com diversões aquáticas; Decreto-Lei n. ${ }^{\circ} 317 / 97$, de 25/03 - Regime de instalações e funcionamento das instalações desportivas de uso público; DecretoLei n. ${ }^{\circ}$ 163/2006, de 08 Agosto - Regime Jurídico da acessibilidade aos edifícios e estabelecimentos que recebem público, via pública e edifícios habitacionais para melhoria da acessibilidade das pessoas com mobilidade condicionada; Despacho Normativo n. ${ }^{\circ} 20 / 2007$ - Cria e regulamenta o Programa de Intervenção do Turismo.

A presença de riscos naturais e/ou tecnológicos de elevada magnitude pode provocar no sector do Turismo grandes impactos em termos de sustentabilidade económica do respectivo destino turístico. Quando nos debruçamos sobre a temática da segurança na sua vertente "safety", rapidamente concluímos ou ficamos com a sensação, que "mais deveria ser feito", ou que "algo ficou por fazer".

\section{Governação do Risco}

A Governação do Risco é um conceito que, em termos gerais, engloba a identificação, a avaliação, a gestão e a comunicação de riscos (fig. 4).

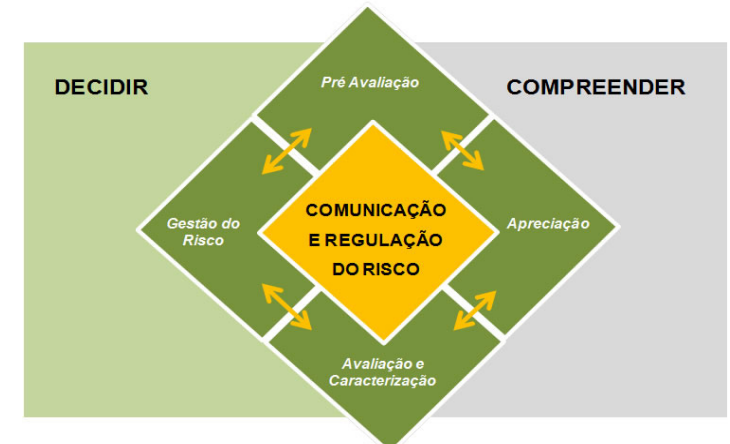

Fig. 4 - Modelo Conceptual para a Governação do Risco. Fonte: Adaptado de IRGC 2005.
A comunicação tem como objectivo a aquisição de conhecimento e a compreensão do risco e do processo de gestão do risco por todas as partes interessadas. Todas as opiniões e pontos de vista devem ser considerados assegurando que todos os participantes no processo conhecem as suas funções e responsabilidades. No processo de gestão do risco há conflitos entre os actores que produzem risco ("risk producers") e os actores que estão expostos a esses riscos. Estes actores designamse stakeholders e são definidos como "socially organised groups that are or will be affected by the outcome of the event or the activity from which the risk originates and/ or by the risk management options taken to counter the risk" (IRGC 2005:49).

O objectivo da governação é alcançar um nível de aceitação dos resultados do processo de decisão entre todos os interesses defendidos pelos vários stakeholders. 0 processo deve primar pelos princípios de inclusão - o quê e quem incluir no processo de governação - não só no processo de decisão mas também no enquadramento das questões, na proposta de opções e na sua avaliação; e de restrição ("closure") quanto à seleção das opções possíveis porque "time and effort of the participants of governance process have to be regarded as spare resources".

No fundo, quanto ao princípio de inclusão, devem ser garantidas as seguintes condições:

- Envolvimento dos vários tipos de partes intervenientes ("stakeholders");

- Garantia de "empowerment" para que todos possam participar activa e construtivamente;

- O enquadramento do problema tenha sido definido em diálogo com os diferentes grupos;

- A inclusão das opções que representam os interesses e valores das partes envolvidas;

- Que tenha sido alcançado um entendimento sobre a magnitude do risco e das opções de gestão do risco em consideração;

- Condução de um fórum de decisão que forneça oportunidades justas e iguais de todos poderem fazer ouvir a voz e as suas preferências;

- Que exista uma clara ligação entre as entidades participantes no processo de decisão e o nível político de implementação.

Não obstante a necessidade de aplicar um princípio de restrição (“closure”), devem ser respeitados os seguintes requisitos de modo a garantir a necessária qualidade das decisões:

- Abordagem de todos os argumentos apresentados e avaliação de todas as alegações lícitas segundo procedimentos de validação acordados por todos; 
- Recolha e processamento de todas as evidências relevantes de acordo com o conhecimento providenciado pelo actual estado da arte;

- Adequada inclusão e processamento de todo o conhecimento sistemático, experimental e prático;

- Consideração de todos os interesses e valores e procura de soluções justas e equilibradas;

- Explicação clara e aprofundada de todas as decisões normativas;

- Aplicação de esforços de modo a preservar a pluralidade de estilos de vida e da liberdade individual.

Se isto for alcançado, ter-se-á conseguido pelo menos uma hipótese de obter consenso e uma melhor aceitação dos resultados da avaliação de opções. A complexidade, incerteza e ambiguidade são típicos da maior parte dos riscos (especialmente riscos globais) pelo que o processo de governação deve ser especificamente definido para o contexto e características de cada risco.

A Governação apela a participação de TODOS, cidadãos, empresas, organismos, ONG's, governos e organizações internacionais e intergovernamentais, procurando integrar nas decisões os contextos culturais e sociais, as opiniões e as preocupações das pessoas, assim como todos os contributos especializados relevantes. A Governação dos Riscos tem que contar com as particularidades especificas de cada risco:

- Âmbito: trata-se de risco local, disperso, transfronteiriço ou global?

- Grau de novidade: e emergente, ou sistémico, e crescente, e corrente, esta institucionalizado?
- É ou não um risco segurável? Ou seja, pode ou não ser transferido?

- Grau de preocupação do público e dos agentes directamente envolvidos.

Saliente-se que conforme muda a categoria do risco, muda o envolvimento dos stakeholders (fig. 5).

Neste domínio, Princípios Reguladores da Governação dos Riscos são:

- Legalidade - enquadramento na legislação nacional, comunitária e internacional;

- Legitimidade - regras e procedimentos normalmente aceites são respeitados;

- Aceitabilidade Social e Ética - conformidade com os padrões sociais e éticos;

- Responsabilização - é providenciada todos os registos e documentos relacionados com prestação de contas e assunção de encargos;

- Eficiência - as providencias tomadas devem ser custo/efectivas;

- Eficácia - as medidas devem atingir o objectivo a que se propõe;

- Sustentabilidade - as medidas mantém a adequabilidade ao longo do tempo;

- Participação - todas as partes interessadas são consultadas;

Receptividade - os pontos de vistas das partes são tomadas em devida conta; Imparcialidade - riscos e eventuais benefícios são distribuídos de forma equitativa.
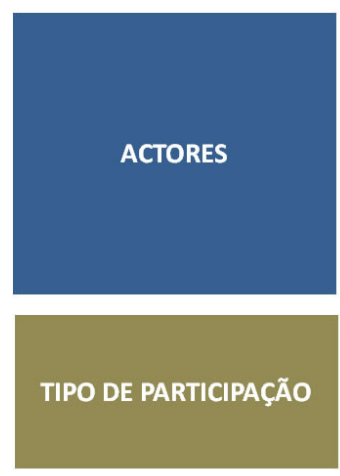

CATEGORIA DO RISCO DOMINANTE

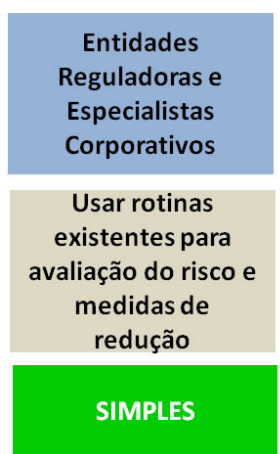

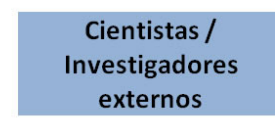

Entidades

Reguladoras e

Especialistas

Corporativos

Maximizar o

conhecimento

cientifico do risco e

opções de

mitigação.

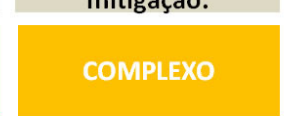

Sociedade Civil
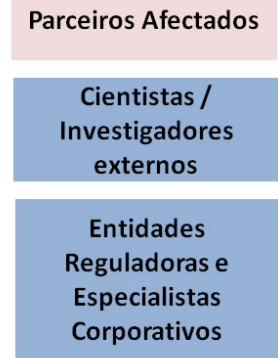

Envolver todos os parceiros afectados para decidir em conjunto o melhor caminho

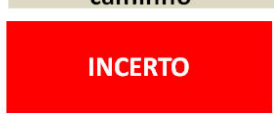

Parceiros Afectados

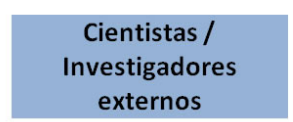

Entidades

Reguladoras e

Especialistas

Corporativos

Debate Social os riscose as suas implicações relevantes

AMBIGUO

Fig. 5 - Regulação da Governação do Risco. Fonte: Adaptado de IRGC 2005 


\section{Governação do Risco no Turismo de Natureza e Aventura}

A segurança é difícil de quantificar do ponto de vista económico e nem todas as empresas consideram relevante o seu investimento, considerando-o muito caro. Não deixando o seu custo elevado de ser um aspecto verídico, o facto é que proporciona grandes vantagens a curto e longo prazo: mais segurança, qualidade de vida, boa imagem e lucro. Neste contexto, pode-se dizer que a segurança constitui um elemento indissociável da rede de ofertas e serviços imbricados ao atendimento turístico, representando um factor importante e condicionante da imagem da cidade como destino turístico.

É importante destacar que os responsáveis pelo turismo e seus profissionais devem proporcionar aos visitantes e aos seus colaboradores um ambiente seguro, e devem compreender que a cautela e a segurança são essenciais para a actividade turística. Neste contexto, é necessária a preocupação com o factor humano, investindo na capacitação e qualificação dos profissionais que prestam serviços turísticos.

O Turismo Activo está em fase de desenvolvimento, é baseado em actividades ao ar livre implicando uma maior interacção do turista com o meio envolvente. A ilha da Madeira possui um território geográfico com espaços incomparáveis para a prática de actividades que implicam contacto directo com a natureza.

Devido às novas necessidades do turista, há cada vez mais actividades ao ar livre ligadas a práticas desportivas em contacto com a natureza. Neste domínio, a qualificação e certificação promovem a diferenciação num mercado cada vez mais dinâmico e exigente na procura de produtos e serviços de excelência. A inovação, segurança e qualidade dos serviços prestados a clientes cada vez mais exigentes, é uma forma positiva de diferenciação. Assegurar a qualidade revela-se na satisfação das necessidades e expectativas dos clientes e na preocupação de uma melhoria contínua dos serviços prestados.

A implementação de regras é essencial para responder às exigências de qualidade e segurança dos praticantes de actividades ao ar livre, nomeadamente através da criação de critérios de Qualidade e Segurança; formação de recursos humanos nas áreas de prevenção, segurança e emergência; promover a utilização sustentada do espaço através da definição de áreas, equipamentos adequados à prática das diferentes modalidades. Neste domínio, surge o Decreto-Lei $n^{\circ} 119 / 2009,19$ de Maio, referentes as condições de segurança dos espaços de jogos e recreio no que respeita à sua localização, implantação, concepção, organização funcional e respectivos equipamentos.

As actividades do Turismo Activo poderão criar situações perigosas, com potencial para o prejuízo, em forma de lesões, ferimentos ou danos para a saúde dos intervenientes, para o património, para o ambiente do local de trabalho, ou uma mistura de todos eles.

Os riscos podem ser graduados em função da probabilidade da sua ocorrência e gravidade e das suas consequências, para cada tipo de risco deve estabelecerse a respectiva quantificação. Os factores que levam a que determinada actividade tenha maior ou menor risco estão associados:

- A competência da gestão, visto que pouca competência da gestão envolve maior risco;

- Idoneidade dos decisores e gestores, comportamento ético e rigoroso diminui o risco;

- Qualidade do sistema de controlo interno e sua eficácia, quanto maior é a eficácia menor é o risco.

A gestão do risco é da responsabilidade de todos os intervenientes, tendo como objectivo identificar oportunidades para evitar ou diminuir as perdas, e/ou reduzir os riscos para um nível aceitável. A avaliação e a gestão do risco não devem ser negligenciadas em qualquer actividade desenvolvida ao ar livre, ou em contacto com a natureza. É fundamental ter presente que qualquer actividade humana segura a cem por cento é inexistente.

A certificação é uma das maneiras de garantir a conformidade do produto, do serviço, do sistema de gestão de uma empresa ou pessoa a requisitos especificados. As empresas utilizam estes instrumentos para se diferenciar e para abrir novos mercados e conquistar novos clientes ou, muitas das vezes, são obrigadas a comprovar por meio da certificação a conformidade de seus produtos, serviços ou de seus sistemas de gestão.

Desta forma a implementação de um sistema de gestão da segurança pode ser uma referência para toda organização envolvida com a prestação de serviços que incluam actividades de turismo de natureza, ou seja, pode ser utilizada por operadoras e por aqueles que recebem os turistas nos destinos, que devem também estar envolvidos no esforço da segurança nas actividades de turismo de natureza.

Um sistema de gestão da segurança para as actividades de turismo de aventura envolve diversos elementos, de maneira a que uma organização possa estabelecer uma política da segurança e possa alcançar os seus objectivos e metas, utilizando as técnicas de gestão de riscos e incorporando o processo de melhoria contínua das condições de segurança. Desta forma, perspectivase que as empresas que actuam no segmento de turismo de aventura possam implementar sistemas de gestão dos perigos e riscos associados a cada actividade. Significa em outras palavras, identificar antecipadamente o que pode acontecer, por quê, como, com que probabilidade e 
com que consequências para os turistas, com a finalidade de servirem de informações básicas para o sistema de segurança aplicado para o turista.

Além de certificar-se tema a segurança física e pessoal garantida, o consumidor deve analisar se a sua condição física é compatível com o programa e, ainda, ficar atento aos cuidados que deve ter na contratação do pacote turístico.

Podemos constatar um carácter único do turismo de aventura baseado no nível de treino e preparação requisitado antes da experiência para lidar com a incerteza e respectivo envolvimento com o risco. A presença do risco nas actividades associadas ao turismo de aventura é cada vez mais um dado adquirido e a incerteza inerente ao ambiente natural aliada às alterações físicas e sensações excepcionais de desequilíbrio, implicam a determinação do nível do risco na configuração das actividades de aventura.

O risco compõe a motivação de muitos turistas por originar a descarga de emoções fortes através da adrenalina. Por outro lado, algumas pessoas precisam perceber um dado controlo desse aspecto para poderem usufruir das sensações.

Considerando que é a presença do perigo que determina o risco e assegura a imprevisibilidade do resultado, tendo por base a norma OHSAS 18001 (Occupational Health and Safety Assestment Series), no contexto da Segurança e Saúde Ocupacional.

- Perigo: fonte ou situação com potencial para provocar danos em termos de lesão, doença, dano à propriedade, dano ao meio ambiente;

- Risco: combinação de probabilidade de ocorrência e das consequências de um determinado evento perigoso. Refere-se às condições de inversão, instabilidade, velocidade, desequilíbrio que as práticas de aventura proporcionam e que são análogas às condições corporais e percepções quotidianas.

Esta diferença auxilia na gestão do risco, através da definição de estratégias de prevenção e planeamento para mitigar o risco. No âmbito do turismo, para que a actividade continue com uma boa procura é fundamental a gestão do risco, a fim de determinar níveis aceitáveis de exposição dos clientes, das empresas e do meio ambiente, garantindo a experimentação das fortes emoções.

\section{Regulação do Risco no Turismo de Natureza e Aventura}

As empresas de animação turística devem identificar e pugnar pelo equilíbrio ideal entre a exposição ao risco e o seu controlo, de modo a garantir a máxima segurança nas actividades. Neste domínio, é crucial a aplicação de legislação e/ou regulamentação de forma eficiente, e em articulação com um sistema de fiscalização coerente com capacidade para garantir qualidade nos serviços, salvaguardando a integridade física dos turistas, a idoneidade das empresas de animação turística e por conseguinte o desenvolvimento deste segmento de mercado.

Vejamos o caso da ABETA - Associação Brasileira das Empresas de Turismo de Aventura, que tem vindo a desenvolver métodos de certificação através de normas técnicas, como por exemplo a implementação de sistemas de gestão da segurança, baseadas na norma OSHAS 18001 para enfatizar a relação entre risco e segurança. Todavia, a segurança no turismo de natureza e aventura é um factor complexo por abarcar diferentes variáveis como: pessoas; equipamentos; procedimentos; sistemas de gestão das empresas prestadoras de serviços; leis e sistemas de fiscalização e controlo existentes em cada município; articulações e logísticas locais disponíveis para buscas e salvamentos e serviços médicos; aspectos climáticos; e, particularmente, os perigos inerentes a cada actividade associados às condições naturais do ambiente onde as actividades das distintas modalidades de aventura são realizadas (BRASIL, 2005). Além desses factores, a ausência de um histórico de ocorrência de acidentes dificulta a compreensão do problema da segurança neste nicho turístico. A existência de uma base de dados com o histórico de acidentes permitir-nosia caracterizar e identificar as principais causas e pontos críticos, bem como definir acções de carácter correctivo e preventivo ao nível do planeamento.

\section{Gestão do Risco no Turismo de Natureza e Aventura}

A incerteza associa-se fortemente ao risco e ao perigo, já que é ela a responsável pela produção de factores de risco. Mas como a percepção da possibilidade de uma situação de risco e a sua avaliação vária de indivíduo para indivíduo, as experiências resultantes das actividades são influenciadas pela percepção do risco. Estes elementos conjugados criam o desafio, cuja natureza pode ser de carácter intelectual, moral, espiritual, emocional ou físico. Contudo o grau do desafio pode ser medido em função do perigo, habilidades e aptidões dos participantes, afectando a intensidade da aventura. Neste domínio, pode-se afirmar que as características de um resultado incerto, risco, perigo e desafio constituem a essência da aventura, uma vez que esses aspectos são fortemente destacados na definição de SPINk et al. (2005) "a aventura refere-se à procura de desafios relacionados com imponderabilidade e imprevisibilidade".

O crescente conhecimento e auto consciência resultante da motivação para explorar e descobrir novos lugares, os quais envolvem a aventura, representam uma 
recompensa ao nível do progresso mental, emocional ou espiritual resultante da experiência (SWARBRooke et al., 2003). A aventura é uma experiência patrocinada pelo entusiasmo que estimula os sentidos, o cérebro e corpo dos praticantes, potenciando uma sensação de entusiasmo que em articulação com a novidade contribui na transferência da experiência quotidiana, conferindothe um carácter de distanciamento da realidade (fig. 6).

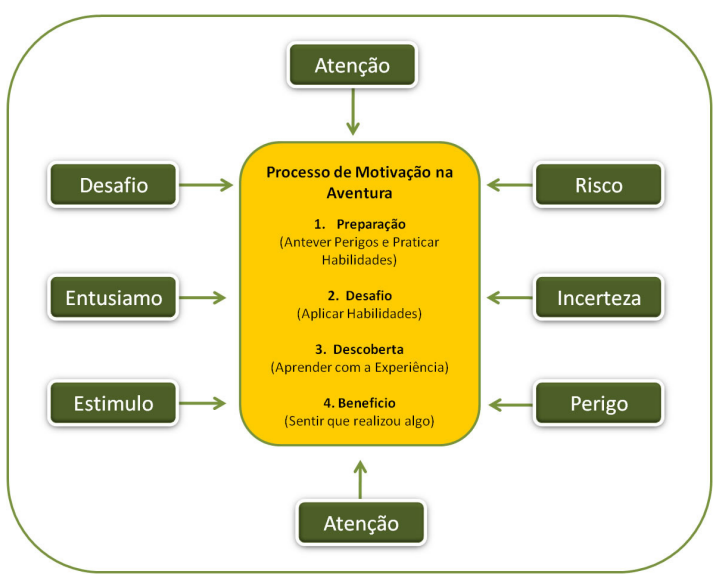

Fig. 6 - A Experiência da Aventura na Natureza. Fonte: SWARBrooke et al., 2003.

Neste domínio, constata-se a existência de diversos estados mentais e emocionais, incluindo a atenção e concentração, uma vez que a aventura é uma experiência emocional. Por esse aspecto, em especial, nota-se a relação com emoções intensas e muitas vezes contrastantes como o contentamento e o desespero, a ansiedade e o prazer, produzidos pelos elementos da incerteza, do risco, do perigo e da novidade. No intuito de contextualizar as características inerentes às experiencias vividas nas actividades de turismo de aventura, SWARBRooke et al. (2003), apresentam os vários estágios da aventura e das percepções e sensações do praticante, evidenciando deste modo a ideia de interdependência.

Considerando a complexidade da aventura, entendese que a definição do segmento turístico que associa esta experiência não é uma tarefa muito fácil. A Organização Mundial do Turismo, em 2003, afirma que o turismo de aventura baseia-se em características naturais e ambientais, como montanhas, rios, florestas, etc. diferentemente dos passeios tradicionais, onde os recursos naturais são apreciados pela sua beleza visual. O turismo de aventura leva a pessoa a um contacto íntimo com o ambiente e torna-o algo a ser desafiado e enfrentado.

Partindo de uma diferenciação do turismo na natureza, a OMT (2003) relaciona o turismo de aventura com a interacção do Ser Humano com o ambiente natural, a partir de actividades que envolvem desafios. Contudo, MILINGTON et al. (2001), apresenta o turismo de aventura como uma actividade de lazer que ocorre num destino original, exótico, remoto ou selvagem, onde os turistas têm a expectativa de enfrentar vários níveis de risco, emoções, tranquilidade, e de serem pessoalmente testados.

Nesta abordagem conceptual o turismo de aventura apresenta-se associado a actividade com o espaço onde esta se realiza (ambiente que proporcione a exploração e a descoberta) e o nível de dificuldade da acção a ser exercida pelo turista (expondo o desafio) com as emoções que a viagem proporciona, a partir do risco e da condição incerta. Desta forma, evidenciam-se como componentes essenciais para a definição deste segmento turístico a necessidade de acção e de empenho por parte do turista face à exposição ao risco e perigos e à ligação com emoções fortes.

O Turismo de Aventura é o segmento de mercado turístico que promove a prática de actividades de aventura e desporto de recreio em ambientes naturais e espaços urbanos ao ar livre que envolvam riscos controlados, exigindo o uso de técnicas e equipamentos específicos, adopção de procedimentos para garantir a segurança e o respeito ao património ambiental e sociocultural.

Estamos perante uma preocupação com a integridade física do turista e com a conservação do património natural e cultural, destacando-se a necessidade de gerir riscos e a adopção de tecnologia. De modo mais abrangente o turismo de aventura vem sendo frequentemente associado com o turismo de natureza, em função predominância do ambiente natural nas práticas de aventura. Mesmo admitindo a forte relação do turismo de aventura com o turismo natureza, destaca-se que um não se limita ao outro, pois lançarse na natureza representa apenas um dos enfoques da aventura, igualmente desafiadores.

Neste contexto podemos verificar traços comuns entre os vários segmentos e formas de turismo, pois implicam uma forte aproximação à natureza e uma experiência emocionante. Por forma, a explicar as semelhanças e diferenças no turismo de aventura e ecoturismo SWARBRooke et al. (2003), definiu três categorias de viagem - turismo de aventura, ecoturismo e pacote de viagem - que dispõem diferentes graus de variáveis como risco, resultado certo/incerto, certeza/segurança, preparação/treino. Para se entender a gestão de riscos aplicada à segurança do turismo natureza de aventura é importante entender onde se inicia o desenvolvimento do processo operacional de segurança no turismo de aventura, conhecer suas etapas, conhecer os métodos de gestão para o planeamento, a organização, a direcção e o controlo de riscos identificados neste segmento do turismo. A segurança é um dos factores que determinam a qualidade na prestação de serviços no turismo de aventura. A percepção de qualidade pelo turista inclui a segurança estabelecida durante a oferta dos serviços prestados. 
A promoção das formas de medições da percepção de qualidade e da segurança do turista, o desenvolvimento das características de segurança, a preparação da base de dados incluindo as características específicas do turismo de aventura, o treino e a motivação de técnicos com especial enfoque em questões ligadas à segurança e qualidade da prestação de serviços e finalmente os papéis exercidos pelas operadoras turísticas na gestão deste segmento de mercado turístico. De acordo WIRTZ (2006), a percepção do turista no turismo de aventura reside, exactamente, na qualidade da prestação de serviços, na oferta no produto prometido, na segurança total dos técnicos que acompanham as actividades e sensação real da adrenalina e dos riscos monitorizados e na sensação do exercício do risco. As actividades mal planeadas geralmente resultam num serviço burocrático, frustrante e de má qualidade e provavelmente deixam os clientes desiludidos.

Da mesma forma, a má gestão destes processos dificulta a boa execução das actividades, resultando numa baixa produtividade dos técnicos e por inerência aumenta o risco de falhas de serviço. Outros factores que são considerados pelo turista na percepção da qualidade são: infra-estrutura oferecida, sistemas de informação, aspectos de treino, pontos de controlo de segurança oferecidos. A percepção da qualidade começa a surtir efeito quando os técnicos que entendem que os controlos são importantes para a gestão de riscos na segurança do turismo de aventura e também que a qualidade depende muito de como tais procedimentos são realizados e controlados e para os turistas que percebem que as actividades serão conduzidas com a segurança e qualidade prometidas. As modalidades ligadas ao turismo activo ou de aventura, apresentam-se de forma atractiva para os turistas pelo facto de estar associada ao risco. Neste contexto na abordagem da gestão da segurança em termos de turismo de aventura é fundamental definir bem conceitos de risco e perigo conforme a norma internacional OSHAS 18001 (Occupational Health and Safety Assessment Series).

Para se entender o grau de importância que tem a gestão de riscos aplicados à segurança do turista no turismo de aventura, é importante analisar os índices de acidentes com base num registo histórico. Para se ter uma noção da situação da segurança oferecida aos turistas no turismo de aventura, é necessária uma pesquisa com particular incidência nos seguintes factores:

- Qual o público que contabiliza maior número de acidentes (masculino/feminino);

- A principal consequência dos acidentes (Tipo de Lesões);

- Necessidade de hospitalização;

- Tipo de falhas que surgem como o principal factor de ocorrência de acidentes;
- Os praticantes preferem a prática por conta própria, dispensando o suporte de agência de turismo/ operadora?

- Procedimentos mais comuns no socorro imediato a vítima (feito no próprio local ou encaminhado para o hospital);

A segurança no turismo de aventura é uma função complexa que envolve pessoas (tanto os clientes ou utentes como os prestadores de serviços); equipamentos, procedimentos; sistemas de gestão das empresas prestadoras de serviços; dispositivos legais e sistemas de fiscalização e controle existentes em cada município; articulações e logísticas locais disponíveis para buscas e salvamentos e atendimentos médicos; factores relacionados com o clima; e evidentemente, os perigos existentes em cada actividade associados às condições naturais (topografia e variações meteorológicas).

A efectiva implantação de um sistema de gestão do risco depende do comportamento das próprias empresas prestadoras dos serviços e de um conjunto de articulações em que o poder público tem papel relevante, não só como orientador, regulador e fiscalizador, mas especialmente no que diz respeito aos sistemas de busca, salvamento e atendimento médico em caso de emergências.

De uma forma geral, os registos actualmente existentes mostram que a frequência de ocorrências não tem relação directa com o grau de risco das actividades: a primeira categoria de vítimas, inclusive fatais, é de pessoas perdidas. A causa parece ser a falta de equipamento e de capacidade de orientação. Outra categoria de causas com alta frequência é a falta de planeamento e avaliação de dificuldades por pessoa ou grupos que se deslocam sem apoio ou orientação especializada.

Nesta categoria, as causas de incidente, acidente e mortes são: falta de alimentos, remédios, vestuários adequados resultando em desidratação, hipotermia, fracturas, etc. Segundo uma lista elaborada pela Fear, da Survival Education Association/Sierra Club, fundada em 1892, as 10 mais frequentes causas de ocorrências que necessitaram de actuação de equipa de busca e salvamento foram:

- Roupa e calçados inadequados;

- Cansaço (por má avaliação do esforço necessário);

- Sede, desidratação;

- Hipotermia, inclusive por desconhecimento de suas causas;

- Má avaliação da dificuldade de uma actividade e das próprias habilidades;

- Alimentação inadequada;

- Pouco ou nenhum planeamento; 
- Itinerário não comunicado para terceiros;

- Falta de capacidade física, psíquica ou ambiental para lidar com problemas;

- Clima (falta de roupa em casos de mudança de clima).

As causas das ocorrências em actividades de maior risco são distribuídas entre erros de procedimentos e falha dos equipamentos. Além desta categoria existem os factores climáticos. Desta forma, para evitar que os acidentes ocorram, é necessário que as empresas definam estratégias de gestão do risco, no sentido de atender oferecer um produto de qualidade. Com tal prática, pode-se também contribuir para a redução do número de pessoas que não procuram as operadoras e agências de turismo especializadas em turismo de aventura.

\section{Comunicação do Risco no Turismo de Aventura e Natureza}

Devido ao carácter complexo das actividades de turismo de aventura, a questão da informação é extremamente relevante, principalmente no que diz respeito à subjectividade do termo "aventura" no entendimento de cada cliente ou potencial cliente. Além disso, a disponibilização de informação a clientes tem sido considerada um factor importante na minimização de acidentes e na transparência da relação com os consumidores, inclusive no cenário internacional.

É fundamental definir competências ao nível da mobilização, desenvolvimento e aplicação de conhecimentos, habilidades e atitudes no desempenho (atendimento; qualidade do serviço; segurança e relacionamento com o meio ambiente e as comunidades envolvidas) e solução de problemas, para optimizar os resultados esperados.

No domínio da segurança, as medidas de contingência passam pela definição de acções preventivas e/ou correctivas a serem adoptadas quando da sinalização ou ocorrência de perigos e riscos. Neste sentido o guia de turismo de natureza e aventura deve ser capaz de cumprir a legislação específica; assumir as responsabilidades pertinentes; planear rotas e medidas de emergência; escolha e preparação de itinerários; planear alternativas em caso de mau tempo ou outros aspectos inesperados; decidir sobre alterações na programação da actividade em função de perigos e riscos; usar fenómenos naturais úteis na previsão do tempo; garantir o uso adequado de equipamentos; liderar grupos (estabelecer limites claros de comportamento e independência dos participantes; assegurar o bem-estar e zelar pela segurança física e emocional dos clientes através da avaliação de factores que contribuam para acidentes; observar sinais de desgaste físico e emocional; recomendar alimentação e vestuário adequados à actividade; assegurar o fornecimento de informações sobre medidas de emergência consideradas; gerir situações de emergência (cuidar de sua sobrevivência; aplicar técnicas de primeiros socorros adequadas a cada situação.

\section{Considerações Finais}

Os impactes da segurança são, em geral, vistos sobre duas perspectivas: macro (enquanto algo que afecta, de uma forma geral, uma sociedade) e micro (o modo como afecta individualmente cada turista). A insegurança gerada num destino turístico por determinados eventos constitui uma preocupação para a indústria turística na medida em que pode ter repercussões na escolha do destino ou na intenção do turista em regressar.

O turismo enquanto fenómeno crucial no contexto da globalização, com incidência particular nos transportes, tornou-se um alvo prioritário para criar instabilidade e insegurança nos viajantes. A forma mais adequada de tornar os destinos turísticos mais seguros passa pelo recurso a campanhas de sensibilização/ informação dos turistas para que estes fiquem mais atentos à sua própria segurança, criando assim uma co-responsabilidade na segurança de quem viaja.

Alguns eventos com consequências lamentáveis ocorridos num passado recente, associado ao comportamento humano impulsionaram a interrogação sobre medidas de segurança e autoprotecção, em especial nas actividades ligadas ao turismo. Saliente-se que na actualidade as questões de segurança (Safety and Security) passam por uma adequada gestão do risco o qual desempenha um papel vital nas actividades desenvolvidas pelas pessoas ao longo de viagens e estadas em locais situados fora do seu enquadramento habitual.

\section{Referências Bibliográficas}

AleXander, D. (2002) - Principles of emergency planning and management. Oxford University Press, New York.

Ayala, Carcedo, F. J. (2002) - “Introducción al análisis y gestión de riesgos”. In Cantos, Jorge Olcina e Arala - Carc edo, Francisco Javier (Ed.) Riesgos naturales, Ariel Ciência, Barcelona.

Ayora, A. (2008) - Gestion Del Riesgo en Montanã y en actividades al Aire libré. Ediciones desnível.

BECK, U. (1992) - Risk society.Towards a new modernity. Sage, London.

BeEDIE, Paul.Chapter7(2003)-Adventure Tourism:Sportand adventures tourism. Edited bySimon Hudson. New York: The Haworth Hospitality Press.

CRavidão, Fernanda Delgado; CunHA, Lúcio (1993) - 
"Ambiente e práticas turísticas em Portugal". Inforgeo, 6, Lisboa.

Cunha, Lúcio; Cravidão, Fernanda Delgado (1998) - "Notas para uma geografia dos desportos radicais em Portugal". Inforgeo.

CURBEt, J. (2005), Turismo y Seguridad: una relación de amorodio, Seguridad Sostenible, [on line], Edición 25, Disponível em: http://www.iigov.org/ss/article.

Fraga, A., (2005), Manual para o investidor em Turismo de Natureza, Bensafrim. Vicentina- Associação para o Desenvolvimento do Sudoeste.

Gama, A. e Santos, N. (1991) - "Tempo livre, lazer e terciário", Cadernos de Geografia, n 10 , Instituto de Estudos Geográficos, Coimbra;

Grunewald, L. (2001) - Seguridad: Manual de Pautas de Seguridad para el Residente y el Visitante de un Destino Turístico, Disponível em: http:// www.paph-oea-cct.com/

Hamaué, Silvio Kimossuke (2008) - Gestão de riscos aplicada à segurança do turismo de Aventura. Dissertação de Doutoramento, São Paulo.

Holсомв, J. e Pizam, A. (2006) - "Do Incidents of Theft at Tourist Destinations Have a Negative effect on tourists decisions to travel to affectd destinations? Tourism, security and safety: from theory to practice, pp. 105-124

HOOD C. (2001) - The government of risk: understanding risk regulation regimes. Oxford University Press.

INFORMATION IN TOURISM CRISIS MANAGEMENT: The Missing Link", In Y. Mansfeld e A. Pizam (eds.),
Tourism, Security \& Safety: From Theory to Practice, Butterworth-Heinemann, Oxford, pp. 271-290.

Julião, R. P., Nery, F., Ribeiro, J. L., Branco, M. C., ZÊZERE, J. L. (2009) - Guia metodológico para a produção de cartografia municipal de risco e para a criação de sistemas de informação geográfica (SIG) de base municipal, Autoridade Nacional de Protecção Civil, Lisboa.

Malta, Paula A. (2000) - "Das relações entre tempo livre, lazer e turismo". Cadernos do Noroeste Série Sociologia, Instituto de Ciências Sociais, Universidade do Minho.

Matos, P. \& Pereira, P. (2003). Aventura Lazer - Actividades Desportivas e Desportos de Aventura.

Morales, S. (2002) - Análisis del Concepto de Seguridad Turística, Disponível em: http://www. integrando.org.ar/turismo/seguridad 01.htm.

Pizam, A. (1994), “Planning a Tourism Research Investigation”, In J. Ritchie e C. Goeldner (eds.), Travel, Tourism, and Hospitality Research: and handbook for managers and researchers, John Wiley \& Sons, New York, pp. 91-104.

Pizam, A. e Mansfeld, Y. (2006), "Toward a Theory of Tourism Security", In Y. Mansfeld e A. Pizam (eds.), Tourism, Security \& Safety: From Theory to Practice, Butterworth-Heinemann, Oxford, pp. 1-27.

ToBIN, G. A. e MonTz, B. E. (1997) - Natural hazards: explanation and integration, The Guilford Press, New York. 